\title{
Engineering Education Quality Assurance within the School of Engineering: A Holistic Approach
}

\author{
Aman Than OO \\ Deakin University, Geelong, Australia \\ aman.m@deakin.edu.au \\ Arun PATIL \\ Deakin University, Geelong, Australia \\ arun.patil@deakin.edu.au
}

\begin{abstract}
BACKGROUND

Quality assurance is a key element of engineering education at Deakin University and is monitored through various mechanisms which also include the process of collecting students' feedback within the Schools and faculties. The information received are then looked at holistically and action plan is developed to implement. This has proven to be very effective to ensure feedback received from the students has been properly addressed. PURPOSE

The School of Engineering at Deakin University, has initiated the formation of Engineering Educational Quality Working Group $(Q W G)$. The aim of $Q W G$ is to provide a focal point for learning and teaching quality and its assurance in undergraduate and postgraduate Engineering courses. The school approach complements Deakin University processes of collecting and analysing student feedback on unit curricula design, delivery and facilitator delivery performance; feedback regarding individual facilitator, unit evaluations and graduate course experiences.

DESIGN/METHOD

The data are collected through face to face feedback from both on and off campus students. Feedback received from the end of trimester student evaluation process was also analysed. RESULTS

The motivation behind the practise is to close the loop for the feedback received from the students and take appropriate action against the feedback. This is to enhance overall delivery of engineering education at Deakin University.

CONCLUSIONS

This paper outlines the activities planned by the QWG and elaborates on quality assurance approaches and key strategies to be implemented by the working group to achieve the desired quality as well as efficacy of those recommendations/actions undertaken at the school level.
\end{abstract}

Keywords: Quality assurance, Quality systems, QA in engineering education, student feedback. 


\section{INTRODUCTION}

The quality assurance at Deakin University is monitored through the process of planning, decision-making, implementation and reporting quality issues based on student feedbacks, unit enhancement and staff peer to peer discussion. Within the School of Engineering, the School's two main operational committees until recently were the Teaching and Learning Committee and the Research Committee. The emphasis of this Quality Working Group (QWG) approach is to promote improvement of quality, not just to ensure quality is maintained. Consequently, shifting the emphasis from quality assurance to quality enhancement (QAA, 2008). Another important objective of the QWG is to provide a formal interface between stakeholder groups (students, industry advisory groups, schools reference group, university administration, employers, etc.) and the school teaching and learning committee in order to enhance teaching and learning quality within the school.

When identifying graduate attributes particularly for undergraduate engineering programs in Australia, the program accrediting body (EA) (EA, 2012) initiates a set of attribute elements mentioned in "Stage 1 competencies and elements of competency". It states that one of the important engineering application ability is application of systematic engineering synthesis and design processes. Every unit outcomes in all engineering courses should meet the standards required by the newly introduced Tertiary Education Quality and Standards Agency (TEQSA, 2012) and Australian Qualifications Framework (AQF) to provide a high quality education to students. The focus of this paper outlines the activities planned by the engineering educational Quality Working Group and elaborates on quality assurance approaches and key strategies to be implemented by the working group to achieve the desired quality as well as efficacy of those recommendations/actions undertaken at the school level.

\section{Engineering Educational Quality Working Group (QWG)}

Author Arun Patil proposed that (Patil et al., 2012) the quality assurance processes in higher education can be carried out at different levels, such as; internal (school/department, faculty or university), external (professional bodies), national (national agencies) and regional or international (international agencies). An initiative process of the learning and teaching in the School of Engineering at Deakin University is to form Engineering Educational Quality Working Group. The aim of QWG is to provide a focal point of learning and teaching quality and its assurance in the Undergraduate and Postgraduate engineering programs. In addition it builds Engineering programs to follow and maintain the Australian Qualifications Framework Standards.

The key objectives of QWG are:

- To create and facilitate strategic approaches for the improvement of quality of learning and teaching in the undergraduate and postgraduate Engineering programs through students feedback (SETU results).

- To monitor key indicators of learning and teaching quality in each and every engineering course units. 
- To summarize feedback from stakeholders, educational partners, students and staff members and make recommendations to the learning and teaching committee for their review and adoption.

\section{Structure and Fuction of QWG}

The QWG role is to provide a summary of the findings/recommendations to the learning and teaching committee for discussion, endorsement and further action. The Engineering Education Quality Working Group members includes:

- Associate Head of School (Teaching \& Learning)

- Course Director for the Bachelor of Engineering Courses

- Heads of Disciplines of Electrical, Civil, Mechanical and Mechatronics courses

- First Year Coordinator

- External member from other universities

The group conducts regular meeting and work on the set targets as planned and devised. The group discusses about the quality issues in learning and teaching, student satisfactory on unit learning outcomes, unit enhancement and staff development.

\section{PLANS/ACTIVITIES}

The QWG works on three main activities within the School of Engineering such as:

\section{Face to face student feedback:}

The School of Engineering collects and evaluates students feedback from various modes. One of such scheme is through face to face feedback. The feedback collected in these forums are collated and compiled by the learning and teaching committee which is utilized by the QWG for the further action. The students feedback comprised of various aspects of learning and teaching and assessment issues. The QWG proposes suggested recommendations to the learning and teaching committee which were then transformed into actions and communicate back to students with proposed actions.

\section{Unit evaluation and enhancement data:}

QWG also collects units data from the Students Evaluation of Teaching and Units (SETU) which is done centrally by the university. Feedback received from each unit is compiled and appropriate actions and recommendation are made.

\section{Staff mentoring on learning and teaching:}

Teaching staff for the units which have low student satisfactions are identified and appropriate support and feedback are provided. This approach is working very effectively and staff are appreciating the support and care given to them. The staff develop the skills to 
better deliver their units and learn to engage with the students better. Excellent learning and student engagement is a positive experience and also a result from quality teaching. Over many decades, researchers believe students will engage more deeply and learn more thoroughly when their teachers care about them to educate, learn, communicate and be innovative in the classroom. From the literature (Anderson, Johnson, \& Milligan, 2000) it is clearly mentioned that academics need the perspectives of students to analyse their experience in practicing and learning a particular approach. It also helps teachers to understand the level of expectation of students in their area of expertise. A teacher must ensure that course design, program structure, teaching and learning assessment should help learners to learn.

Peer review of teaching is a well-established practice in many academic environments. In Australian universities, the aim of peer review teaching is to enhance learning and teaching. In peer reviewed teaching, staff members obtain an opportunity to share their professional responsibilities that enhance learning and teaching approaches. The benefits of peer reviewed teaching for individual staff members are shown below:

- Improving professional relationships with colleagues.

- Developing teaching practices from peer feedback.

- Sharing broader knowledge of curriculum and implementing new teaching ideas.

- Enhancing student assessment and learning outcomes.

\section{CONCLUSION}

From 2012 onwards the school has implemented a more holistic structure of quality and assurance. The school now has an overarching Board of Studies (BoS) committee responsible for final approvals of all school functions prior to submission to faculty and university committees. The learning and teaching committee is responsible for innovation and alignment of local, national, and international initiatives to the school. The integration of student feedback from various resources help to enhance the quality assurance process of academic programmes, which also provide valuable improvements for engineering classrooms, practical learning, design thinking in an engineering education environment.

The QWG aim is to enhance the quality of learning and teaching for all engineering programs in the School of Engineering at Deakin University. The engineering teaching staff at Deakin University seem to have an adequate understanding of quality assurance, which will help QWG to perform the future plan and activities mentioned above. This is encouraging to the School of Engineering, which will enhance student learning and staff teaching processes to better align with the learning and teaching model. The formation and activities of QWG in the School of Engineering at Deakin University is a key hub for all learning and teaching enhancement activities within the School to improve learning/teaching and assessment, student satisfaction and systems development. 


\section{REFERENCES}

Anderson, Don, Johnson, Richard, \& Milligan, Bruce. (2000). Quality assurance and accreditation in Australian higher education: An assessment of Australian and international practice.

EA. (2012). Stagel competency standard for professional engineer. Australia: Engineers Australia.

Patil, Arun, Nair, Chenicheri Sid, Miller, Jo, Maung Than Oo, Amanullah, Keleher, Patrick, \& Martin, Fae. (2012). Engineering education quality enhancement: a case study at the School level in the University. Studies in Learning, Evaluation, Innovation \& Development, 9(1).

TEQSA, The Tertiary Education Quality and Standards Agency. (2012). Report of an Audit of Central Queensland University (Retrieved August 30 ed.).

University, Deakin. (2014). Learning@Deakin. from http://www.deakin.edu.au/learning 